\title{
Video Monitoring of Shoreline Positions in Hujeong Beach, Korea
}

\author{
Yeon S. Chang ${ }^{1}{ }^{(D}$, Jae-Youll Jin ${ }^{2}$, Weon Mu Jeong ${ }^{3}$, Chang Hwan Kim ${ }^{4}$ and Jong-Dae Do ${ }^{2, * \mathbb{D}}$ \\ 1 Coastal Development and Ocean Energy Research Center, Korea Institute of Ocean Science and Technology, \\ Busan 49111, Korea; yeonschang@kiost.ac.kr \\ 2 Coastal Morphodynamics Team, Korea Institute of Ocean Science and Technology, Busan 49111, Korea; \\ jyjin@kiost.ac.kr \\ 3 Maritime ICT R \& D Center, Korea Institute of Ocean Science and Technology, Busan 49111, Korea; \\ wmjeong@kiost.ac.kr \\ 4 Dokdo Research Center, Korea Institute of Ocean Science and Technology, Busan 49111, Korea; \\ kimch@kiost.ac.kr \\ * Correspondence: jddo@kiost.ac.kr; Tel.: +82-54-780-5305
}

Received: 1 November 2019; Accepted: 18 November 2019; Published: 20 November 2019

Featured Application: The video monitoring system and mobile light detecting and ranging (LiDAR) used in this study can be applied for erosion control in beaches with various bedforms and coastal structures.

\begin{abstract}
Shoreline processes observed by a video monitoring system were investigated under different wave conditions. A $30 \mathrm{~m}$-high tower equipped with video cameras was constructed in Hujeong Beach, South Korea, where coastal erosion was suspected to occur. Two-year shoreline data since December 2016 showed that beach area, $A_{b}$, has decreased, but periods of rapid increase in $A_{b}$ were also observed. Shoreline change was closely related to the wave propagation directions and bottom topography. $A_{b}$ increased when waves approached the shore obliquely, whereas it decreased when they approached in a normal direction. The shoreline became undulated when $A_{b}$ increased, while it became flatter when $A_{b}$ decreased. The undulation process was influenced by nearshore bedforms because the shoreline protruded in the lee area where underwater rocks or nearshore sandbars actively developed, with a sheltering effect on waves. Specifically, the locations of shoreline accretion corresponded to the locations where the sandbar horns (location where a crescentic sandbar protrudes toward the shore) developed, confirming the out-of-phase coupling between sandbars and shoreline. When waves with higher energy approached normal to the shore, the sheltering effect of sandbars and underwater rocks became weaker and offshore sediment transport occurred uniformly along the coast, resulting in flatter shorelines.
\end{abstract}

Keywords: video monitoring; coastal erosion; shoreline change; nearshore sandbars

\section{Introduction}

Coastal erosion is a serious problem that may cause economic and environmental damage to the coastal communities. For proper protection of coastal environments, a systematic management of the coastal zones must be implemented by the government together with local communities. Such management strategies should be built based on scientific information, which provides proper tools to understand the status of the coasts, and accurate monitoring of the on-going coastal processes, which is required to produce long-term data.

Since the first technique using remotely sensed video images was introduced to measure the morphology and scale of sand bars [1], video monitoring techniques have been widely applied to 
detect shoreline positions [2,3] as a tool for coastal zone management [4]. For example, 40 video monitoring systems have been employed in the beaches along the coasts of South Korea to calculate the seasonal and annual variation of beach areas, and these data have been used to develop coastal management plans.

Along with their applications for coastal management, video systems have also been used for scientific applications to measure nearshore hydrodynamic processes such as longshore currents [5] and wave parameters [6,7]. In addition, they have been applied successfully in engineering practices such as evaluating the performance of beach nourishment [8]. Video systems are also advantageous to monitor short-term beach processes. During extreme storm events, the shoreline could be rapidly changed in a few days, and the erosion and recovery process could be analyzed using video cameras [9]. One of the greatest benefits of video monitoring over point monitoring is its wider spatial coverage achieved by processing obliquely captured image data [10]. Specifically, it provides significant advantages in monitoring complex shorelines where nearshore processes do not occur homogeneously, and thus, the shoreline change pattern becomes irregular due to the existence of rocky seabeds or nearshore sandbars.

In this study, we analyze the shoreline variations in Hujeong Beach, South Korea, where a video monitoring system has been operating since December 2016. Hujeong Beach is characterized by active development of nearshore sandbars and as a result, its shoreline has a complex pattern with significant variations over time. In addition, there are parts of the seabed that are covered by rocks, although most parts are covered by sand, which makes the shoreline pattern more complicated. The goal of this study is, therefore, to examine the shoreline variations in Hujeong Beach that have been specifically affected by the existence of nearshore sandbars and underwater rocks in relation to the wave conditions. Although the video monitoring system itself is similar to those employed in previous studies, we believe the results of the present work are valuable as the shoreline variation data shows characteristic patterns according to the combined effects of bedforms and waves. Therefore, we used the wave data that were continuously measured during the two years of the experimental period at approximately $1 \mathrm{~km}$ offshore from the coast, which increased the reliability of the data in correlation with the shorelines. In addition, the shoreline positions estimated by the video cameras may contain errors when averaging the images to remove noise; thus, validation of the video data is required. For validation, we additionally employed a ship-mounted mobile light detecting and ranging (LiDAR) instrument to measure the beach topography outside the water.

\section{Video Monitoring System}

The video monitoring system was constructed in the middle of Hujeong Beach, which is on the east coast of South Korea (Figure 1a). In the northern end of the beach, an intake breakwater is located to protect the intake system of the Hanul nuclear power plant (NPP), as shown in Figure 1b [11]. This breakwater does, however, block the sediments that are discharged from Bugu River to be transported south to Hujeong Beach. Therefore, the beach is vulnerable to erosion because the input amount of sediments has decreased due to the breakwater whereas they are still lost to the southeast of the beach through Jukbyeon Port. To monitor this process, the East Sea Research Institute (ESRI) of the Korea Institute of Ocean Science and Technology (KIOST) has operated the video monitoring system since December 2016.

In total, eight video cameras were installed on top of a $30 \mathrm{~m}$-high metal tower. The height of the tower was determined to obtain secure angles for the cameras because berms have occasionally formed along the beach shore causing blind spots. The coverage of the monitoring system is $\sim 2.4 \mathrm{~km}$, with $\sim 1.2 \mathrm{~km}$ at either side of the tower. The cameras capture images every second. Figure 2a shows a picture of the video monitoring tower constructed at S1, and a magnified view of the top of the tower where the video cameras were installed is shown in Figure 2b. In Figure 2c-i, snapshots taken by each of the cameras are shown as an example of the image data. To extract the shoreline data more precisely, 600 snapshot images are averaged over $10 \mathrm{~min}$ to remove the noise produced by wave breaking [12]. 
Every hour, only the first $10 \mathrm{~min}$ of data were averaged to produce one representative image of the hour. As the images were not visible during the night, only 12-15 image data were available per day to be processed for the estimation of shoreline positions. The image data were transferred to the processing center using an internet network system [13]. Once the 600 snapshot images were averaged, the shoreline area appeared as a white narrow band due to the swash zone. The shorelines were manually extracted from these averaged images by taking a line in the middle of each band. Because errors in this extraction process might increase when the waves were actively breaking, the extracted shoreline data were accepted only when the band widths were narrow under mild wave conditions (wave heights $<0.5 \mathrm{~m}$ ).

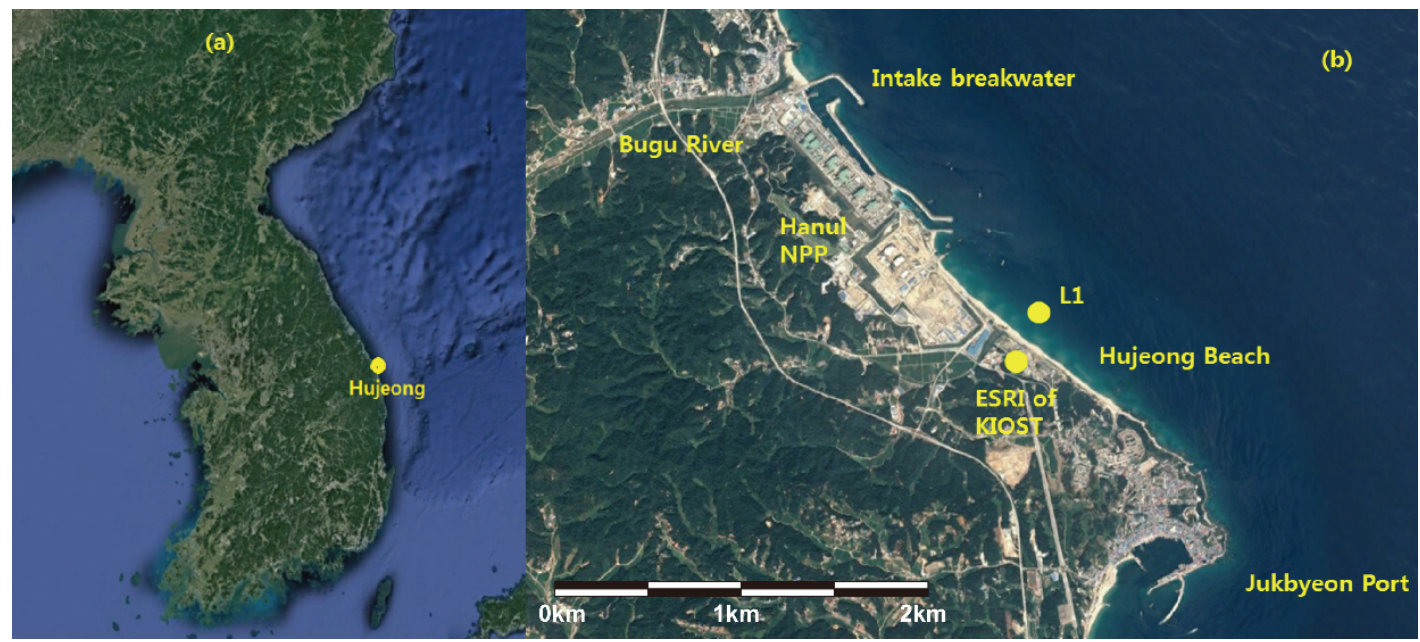

Figure 1. (a) Location of Hujeong Beach; (b) map of Hujeong Beach with location of the video monitoring system (L1). This figure is taken from [11].

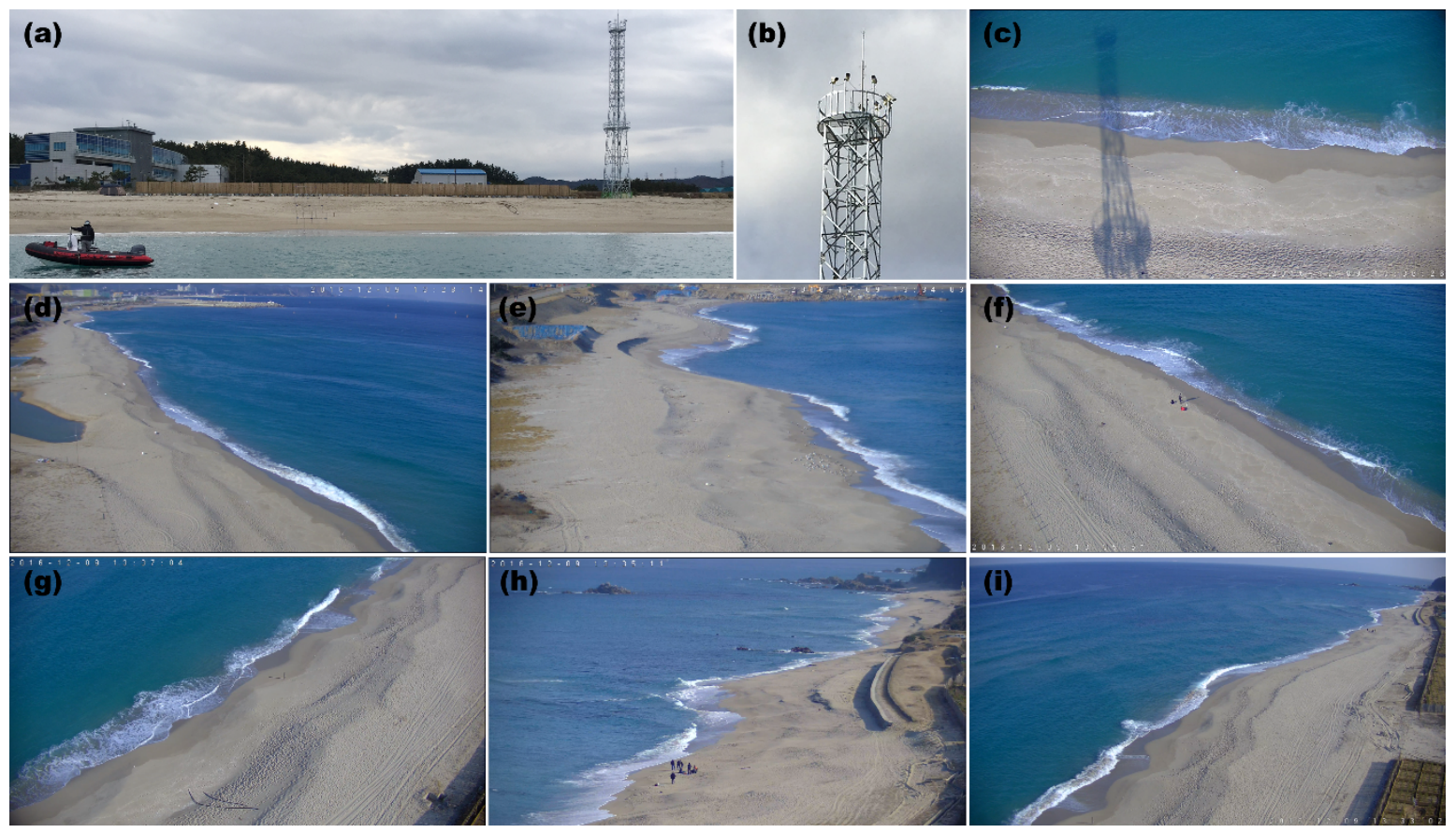

Figure 2. (a,b) Photographs of the video monitoring tower installed in Hujeong Beach, December 2016. (c-i) Examples of shoreline image data measured by the video cameras. These images are taken from [12]. 
The shoreline positions that are obtained by averaging the snapshot images may contain errors when removing the noise by wave breaking, which requires validation of the data. Figure 3 shows a comparison of the shoreline position data estimated by the video monitoring system with beach topography data outside the water. The land topography data were measured by a mobile LiDAR that was mounted on a boat on 12 March 2017. The mobile LiDAR was equipped with a real time kinematic (RTK), global navigation satellite system (GNSS), and inertia measurement unit (IMU). Ship-mounted mobile LiDARs have advantages over the land-based mobile LiDARs as they can survey a larger area relatively fast by exploring along the coastline. The mobile LiDAR has a measurement range of $1 \mathrm{~km}$ and a scanning range up to $80^{\circ}$ in the vertical and up to $360^{\circ}$ in the horizontal, with accuracy of $2 \mathrm{~cm}$. As shown in Figure 3, the shoreline positions estimated by the video monitoring system accurately match the positions measured by the mobile LiDAR. Discrepancies can be found specifically near the areas where the horizontal gradient of the shoreline is relatively large. However, the maximum error of the shoreline position is of approximately $10 \mathrm{~m}$ and the resulting error in the estimation of beach area is less than $3 \%$, which validates the application of video monitoring data for this study.

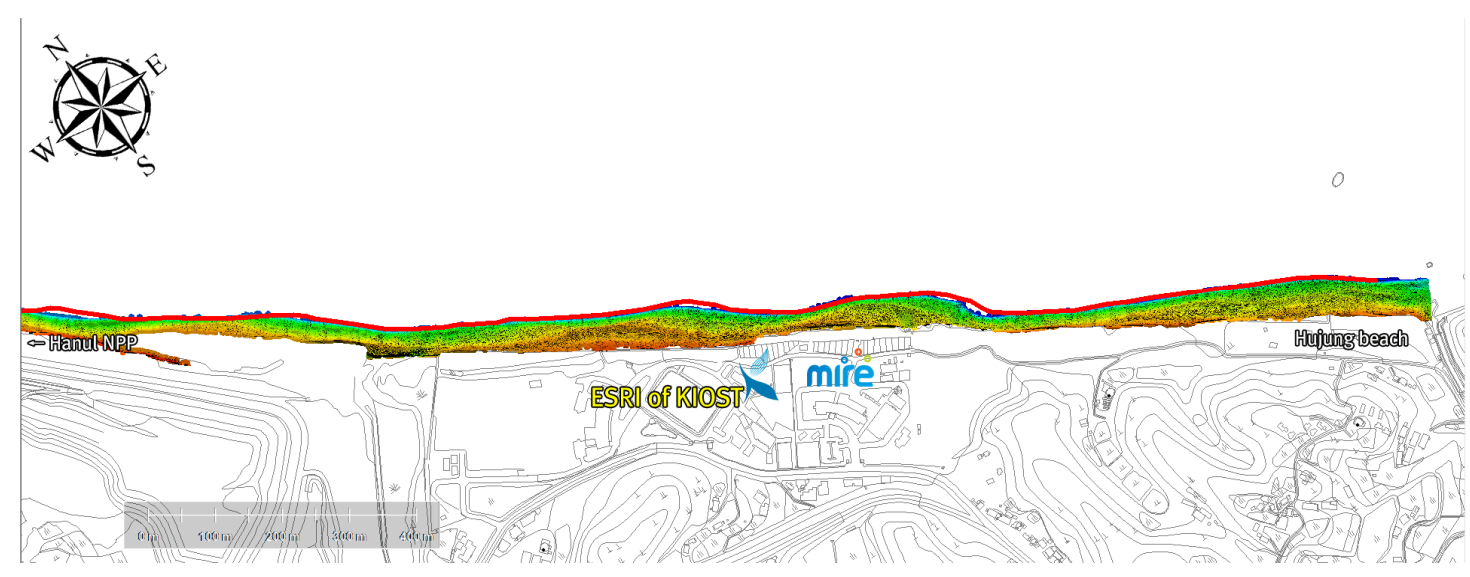

Figure 3. Comparison of shoreline positions estimated with the video monitoring system (red solid line) with land topography (green and yellow contours) measured by a ship-mounted mobile LiDAR on 12 March 2017. The seaward boundary of the colored contours determines the shoreline positions.

\section{Experiment}

The image data collected by the video monitoring system have been processed to calculate the area of Hujeong Beach, $A_{b}$, since December 2016 by positioning the coastline from the averaged images. In Figure 4, the time variation of the calculated beach area is plotted until October 2018. During the period of approximately two years, $A_{b}$ generally decreased, although there were periods when $A_{b}$ significantly increased from October 2017 to February 2018. From this time series of $A_{b}$, we selected four terms (T1, T2, T3, and T4) that showed a specific pattern of beach area variation. T1 was chosen during the period from 9 December 2016 to 18 March 2017, when $A_{b}$ significantly fluctuated with an increase in the resulting area at the end of the term. In T2 (8 June 2017 to 29 October 2017), $A_{b}$ steadily decreased, losing a total beach area of $\sim 10 \%$. T3 was selected because $A_{b}$ increased rapidly during a relatively short period from 29 October 2017 to 23 December 2017. On the contrary, $A_{b}$ significantly decreased during T4 from 13 March 2018 to 15 August 2018. The start and end times of each period are listed in Table 1, and the measurements of $A_{b}$ at the corresponding time steps are listed in Table 2. 


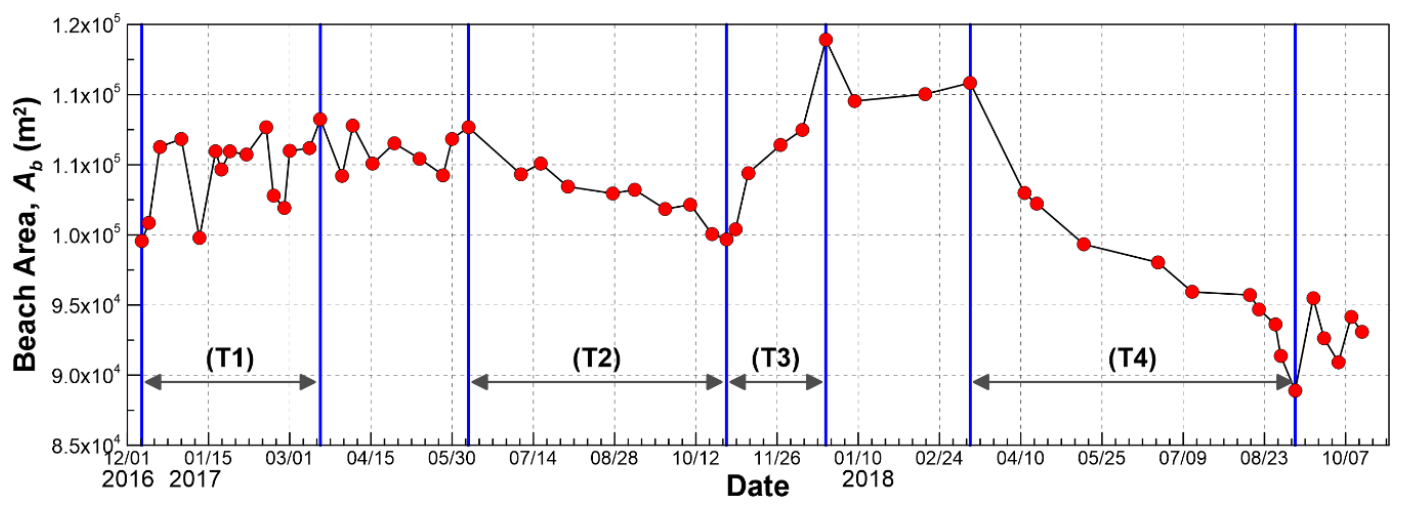

Figure 4. Time variation of beach area, $A_{b}$, from 1 December 2016 to 7 October 2018. T1, T2, T3, and T4, marked by the blue vertical lines, denote the time periods selected for the analysis during which $A_{b}$ shows a specific variation pattern.

Table 1. Start and end dates of the four selected periods.

\begin{tabular}{ccccc}
\hline Dates & T1 & T2 & T3 & T4 \\
\hline Start & 9 December 2016 & 8 June 2017 & 29 October 2017 & 13 March 2018 \\
\hline End & 18 March 2017 & 29 October 2017 & 23 December 2017 & 15 August 2018 \\
\hline
\end{tabular}

Table 2. Beach area measured at the start and end dates of the four selected periods.

\begin{tabular}{ccccc}
\hline Beach Area $\left(\mathbf{m}^{\mathbf{2}} \mathbf{)}\right.$ & T1 & T2 & T3 & T4 \\
\hline Start & 99,557 & 107,674 & 99,680 & 110,841 \\
\hline End & 108,247 & 99,680 & 113,904 & 88,914 \\
\hline
\end{tabular}

In Figure 5, the shoreline positions in Hujeong Beach, $y_{t}$, are compared at three different times: (1) 9 December 2016, when the video monitoring data started to be measured; (2) 23 December 2017, when $A_{b}$ became maximum at the end time of T3; and (3) 9 September 2018, when $A_{b}$ was minimum at the end time of T4. It is interesting to find out that there are locations (L1, L2, L3, and L4) where $\Delta y_{t}$ was greater than the other areas. The reason for this non-homogeneous $y_{t}$ evolution along the shoreline is probably related to the nearshore sandbars and rocky seabeds that are observed at 3-5 m water depth. For example, Figure 5b shows a satellite image around the four locations from L1 to L4 on 20 April 2018 (T4), captured from Google Earth. Google Earth images are constructed based on the data from Landsat satellites. Landsat images were employed to show the shallow water seabed topography when the images are reflected through the water column under clear weather conditions [14,15]. The Google image in Figure 5 shows that crescentic sandbars actively develop in the nearshore area of the beach, specifically near L1 and L2. Besides the sandbars, underwater rocks are abundantly observed around L3 (black dots inside rectangle R1). In addition, small rocky islands and underwater rocks around the islands are found to be located near L4 within rectangle R2. These sandbars and rocky seabeds, along with the incoming waves, affected the shoreline change pattern during the periods, which will be examined in the next section. 


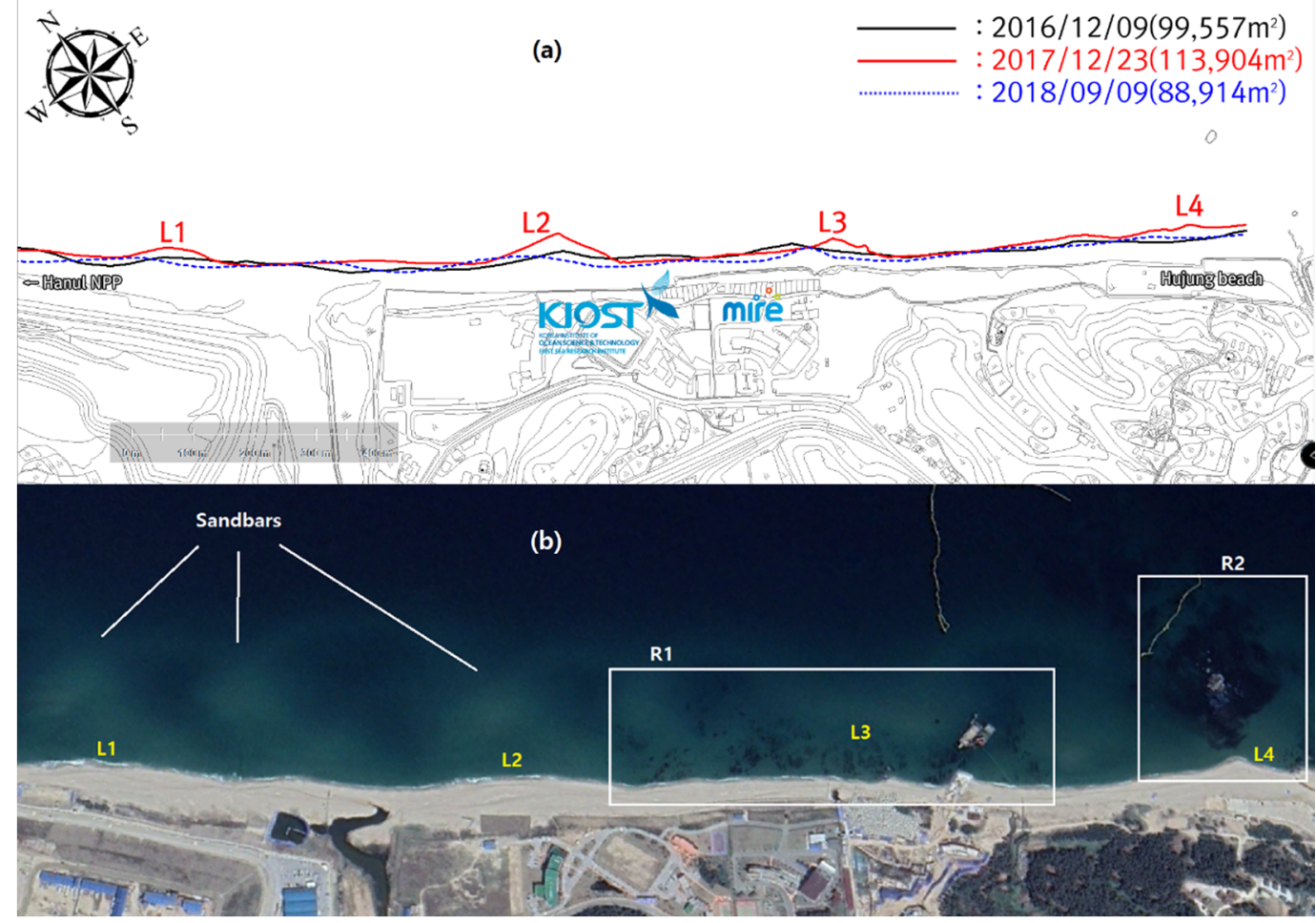

Figure 5. (a) Comparison of shoreline positions, $y_{t}$, measured on 9 December 2016 (start date of data collection), 23 December 2017 (when $A_{b}$ became maximum at T3), and 9 September 2018 (when $A_{b}$ was minimum at T4). L1, L2, L3, and L4 denote the locations where the shoreline positions, $y_{t}$, significantly changed during the period. (b) Satellite image on 20 April 2018 (T4), captured from Google Earth. The white rectangles, R1 and R2, denote the locations where underwater rocks develop near L3 and L4, respectively. The figure also shows the development of nearshore sandbars, indicated with the white lines.

\section{Results}

In Figure 6, $y_{t}$ at two times-beginning and end times of T1-are compared. The red and blue colors filled in-between the two lines denote the advance and retreat, respectively, of the shoreline during T1. In the figure, a rose diagram that shows the distribution of the propagating wave heights, $H_{w}$, and directions, $D_{w}$, is also drawn to support the understanding of the shoreline evolution pattern. $H_{w}$ and $D_{w}$ were estimated from the wave spectra based on the wave data measured by KIOST using Nortek Acoustic Waves and Currents (AWAC) at the location of $\sim 19 \mathrm{~m}$ depth and $\sim 1.0 \mathrm{~km}$ away from the coast. For the three-month period of $\mathrm{T} 1$ when $A_{b}$ significantly fluctuated by repeatedly losing and gaining the total beach area, $\Delta y_{t}$ shows an inconsistent pattern along the coastline because the shore significantly advanced at L3 and L4 while it decreased at L1 and L2. In this period, $~ 50 \%$ of the waves approached the shore in NNE direction (slightly inclined to the north) and $\sim 30 \%$ of the waves approached the shore in the normal direction $\left(D_{w}=\mathrm{NE}\right)$. Regarding the propagating wave heights, $\sim 20 \%$ of them were high waves with $H_{w}>2 \mathrm{~m}$. Therefore, the shoreline accretions at L3 and L4 were caused when shadow zones were formed by the obliquely approaching waves in the lee area of the underwater rocks developed in R1 and the rocky island in R2. These inclined waves could produce longshore sediment transport to the southeast direction along the beach. In the shadow zones behind the rocks, however, the sediment transport rates were reduced to cumulate sediments, specifically in L3 and L4, which can be easily understood from a simple consideration of the continuity equation for the one-line theory [16] as

$$
h_{p} \frac{d y}{d t}+\frac{d Q}{d x}=0
$$


where $h_{p}$ is the active profile height, $y$ is the shoreline position, and $Q$ is the longshore sediment transport. According to Equation (1), therefore, the shoreline would advance $(\Delta y>0)$ if the sediment transport rate decreases $(\Delta \mathrm{Q}<0)$, as observed in L3 and L4. At locations near L1 and L2, $y_{t}$ slightly advanced to the sea. This shoreline change may be related to sandbar development as shown in Figure $5 b$, which will be discussed later in this section.

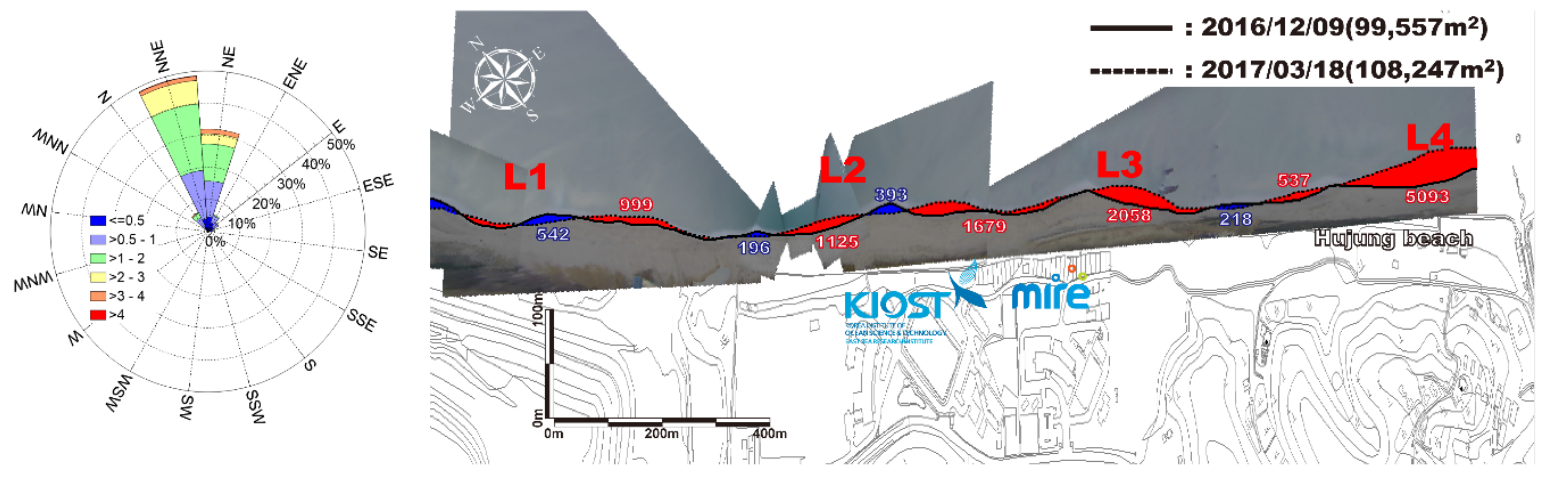

Figure 6. Comparison of $y_{t}$ between two different time steps measured at the beginning of $\mathrm{T} 1$ (9 December 2016) and at the end of T1 (18 March 2017) along the coastline. The red and blue colors filled in-between the two lines denote, respectively, the advance and retreat of the shoreline during T1. The numbers denote the magnitude of the gained and lost area in the corresponding colors $\left(\mathrm{m}^{2}\right)$. The rose diagram shows the $H_{w}$ and $D_{w}$ distributions measured during the period.

Figure 7 compares the shoreline positions at the beginning and end time of $\mathrm{T} 2$ with a rose diagram of the wave conditions. It shows that the shoreline generally retreated for a $\sim 4.5$-month period by losing $\sim 7 \%$ of the beach area, which can be estimated from Figure 4 . The loss of sediments during this period is unexpected considering the relatively lower wave energy compared to $\mathrm{T} 1$ because $~ 95 \%$ of the incoming waves had $H_{w}$ lower than $2 \mathrm{~m}$. As for $D_{w}$, the directional spectrum is wider compared to $\mathrm{T} 1$ but the majority of the waves approached the shore in the normal direction, which reduced the amount of sediments that moved in the longshore during the period. Instead, more sediments were probably transported in the cross-shore direction. For example, the shoreline at the end time of $\mathrm{T} 2$ became flatter compared to that at the beginning time, when the shoreline was more severely undulated. During $\mathrm{T} 2$, therefore, wave forces acted uniformly along the coast regardless of the existence of underwater rocks under normal direction approaching wave conditions. The rose diagram in Figure 7 shows that extreme wave conditions with $H_{w}>4 \mathrm{~m}$ were observed ( $\sim 5 \%$ of total waves). These high waves probably contributed to the erosive process. It should be noted, however, that the beach area gradually decreased during T2 instead of having a specific time of rapid reduction in $A_{b}$, and thus, the impact of extreme waves on the shoreline change is still not clearly identified based on the wave data.
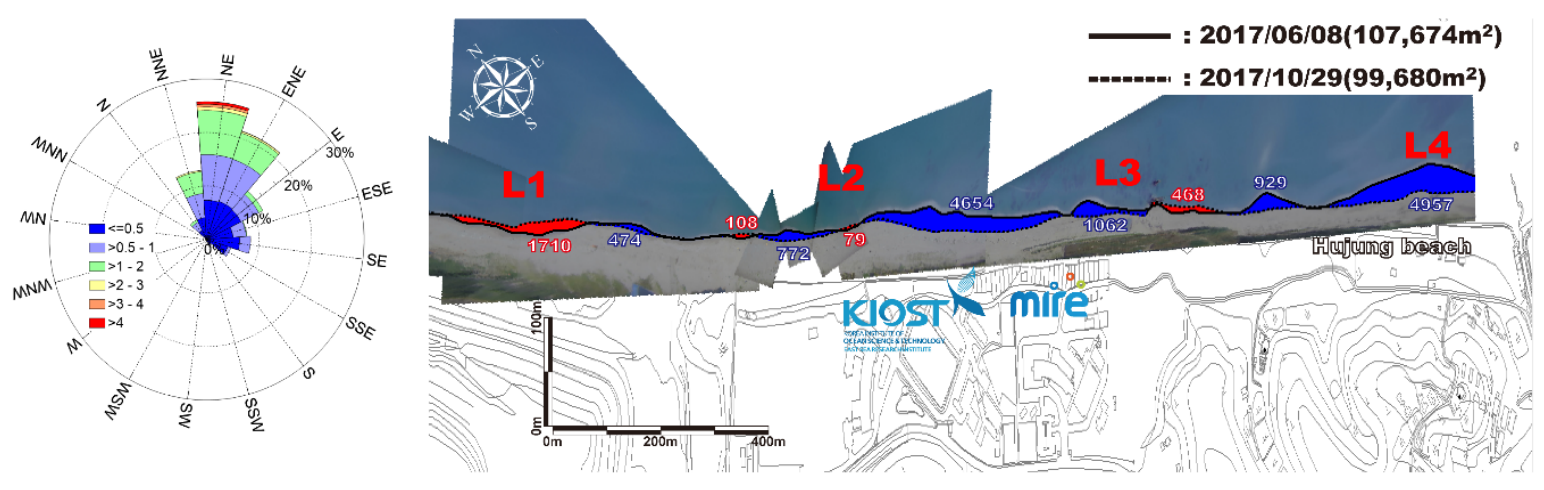

Figure 7. Same comparison as that in Figure 6 but measured at the beginning (8 June 2017) and end (29 October 2017) of T2. 
Figure 8 shows the shoreline positions at the beginning and end time of T3 (29 October to 23 December 2017) with the corresponding rose diagram of wave conditions. It is interesting to find out that $A_{b}$ increased $\sim 15 \%$ during the three-month period. Specifically, the shoreline significantly advanced at the four locations from L1 to L4. The wave conditions in T3 were similar to those in T1 as most of the incoming waves propagated obliquely from the north of the beach $\left(D_{w} \sim \mathrm{NNE}\right)$. Therefore, shadow zones were formed to cause the shoreline accretion at L3 and L4 where underwater rocks developed, as was observed in the case of T1. One of the differences in the shoreline evolution pattern between T1 and T3 is that the shoreline was significantly advanced at L1 and L2 in T3, which was not observed in T1. For example, $\Delta y_{t}$ became maximum at L2 and it was also dominant at L1 in T3, while $\Delta y_{t}$ showed no clear changes at these locations in T1. As already mentioned, the significant shoreline changes at L1 and L2 were related to the development of nearshore sandbars.

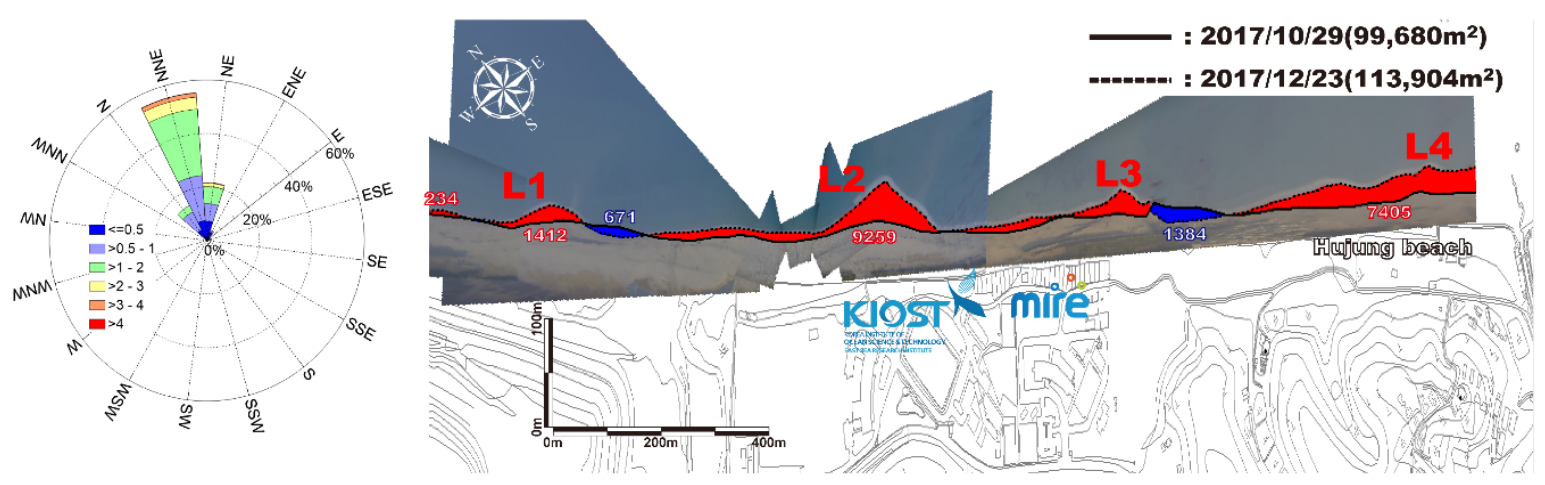

Figure 8. Same comparison as that in Figure 6 but measured at the beginning (29 October 2017) and end (23 December 2017) of T3.

Figure 9 shows the seabed elevation changes in Hujeong Beach between 18 November 2016 (before T1) and 12 March 2017 (after T1) [17]. The bottom topography was measured using echosounders and a mobile LiDAR. The changes in seabed elevation show that nearshore sandbars actively developed parallel to the shoreline, in the area with water depth shallower than $5 \mathrm{~m}$. The development of sandbars can be confirmed with the Google image shown in Figure $5 \mathrm{~b}$ because crescentic sandbars are observed near the locations of L1 and L2 on 20 April 2018 (T4). The figure also shows that the shoreline is advanced to the offshore at the locations where the horns of the sandbars developed near L1 and L2, although the underwater rocks do not develop in these areas. It should be noted that these locations of the shoreline accretion correspond to the locations where the horns of the sandbars developed, which shows a good example of out-of-phase coupling between the sandbars and shoreline $[18,19]$. Therefore, the dominant shoreline accretions at L1 and L2 indicate that nearshore crescentic sandbars might be actively developed at T3, and the shoreline was advanced at the locations corresponding to the sandbar horns. Compared to T1, the wave energy in T3 was lower as the waves with $H_{w}>2 \mathrm{~m}$ were $\sim 7 \%$ of total incoming waves in this period, which might provide favorable conditions to form crescentic sandbars as a result of positive feedback between the nearshore flow circulation, sediment transport, and the morphology itself [18]. 


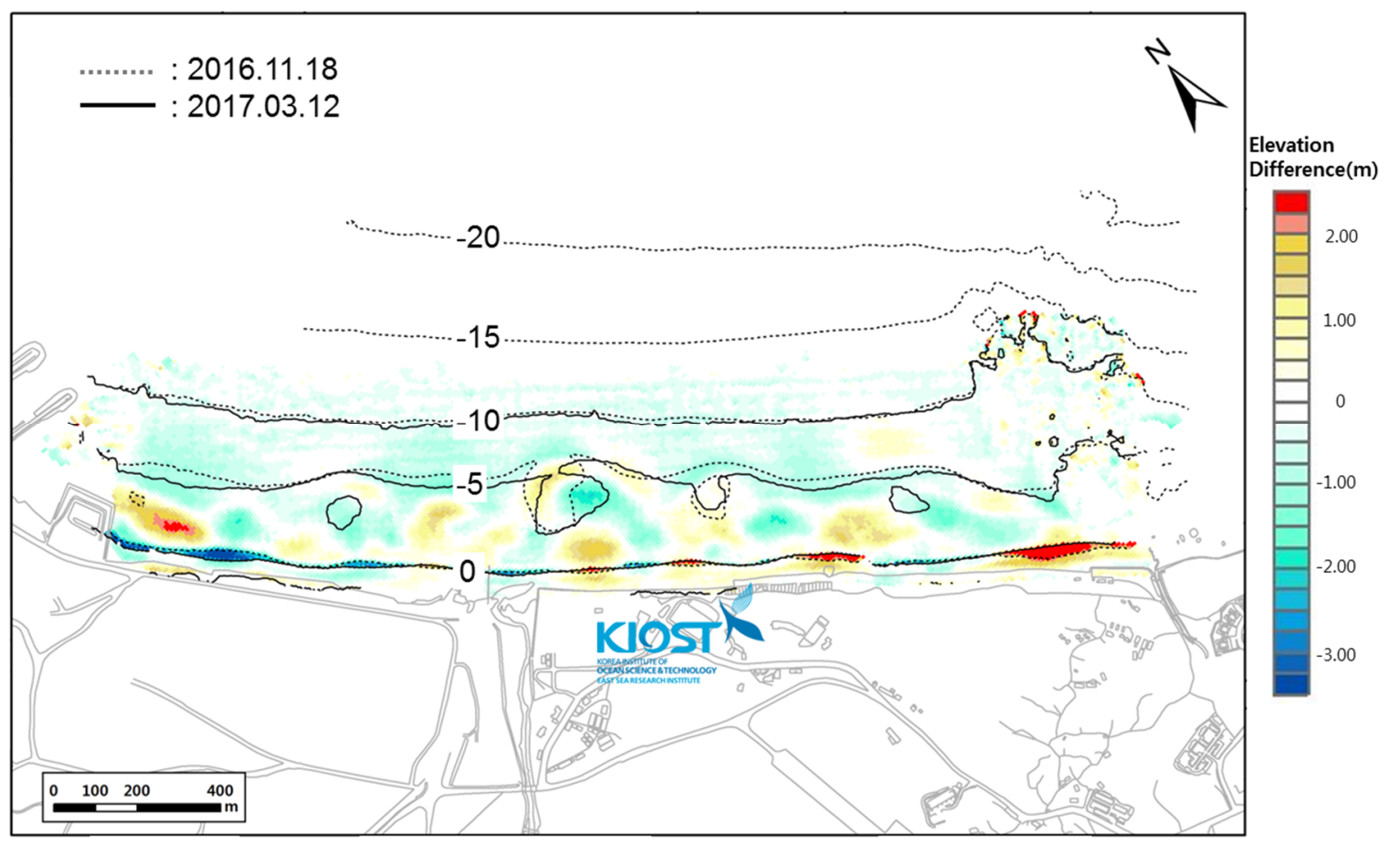

Figure 9. Seabed elevation changes in Hujeong Beach between 18 November 2016 (before T1) and 12 March 2017 (after T1). The figure is taken from [17].

Figure 10 shows another example of significant shoreline change between the beginning and end time of T4 (13 March to 15 August 2018), when $A_{b}$ decreased $19 \%$. The shoreline was generally retreated along the entire coast, but the reduction in $y_{t}$ was particularly greater at L2 and L4. As shown in Figure 9, the shoreline accretion at L1 and L2 during T3 was due to the nearshore sandbars. Therefore, the shoreline retreat at the corresponding locations might also be related to the sandbars, which could occur when the sandbar development became weaker during T4. It should be noted that the wave conditions in $\mathrm{T} 4$ can be distinguished from those in periods T1-T3. The wave conditions in T4 were generally similar to those in T3 because the wave energy was moderate as $\sim 10 \%$ of $H_{w}$ was higher than $2 \mathrm{~m}$. However, compared to the other cases, $D_{w}$ spread in wider angles, showing that the waves were approaching in various directions. Interestingly, $20 \%$ of $D_{w}$ were SE and ESE, and this indicates that the waves approached parallel to the shore from the south. These shore-parallel waves might significantly affect the shoreline changes by transporting the sediments along the shoreline regardless of the relatively low wave energy $\left(H_{w}<1 \mathrm{~m}\right)$.
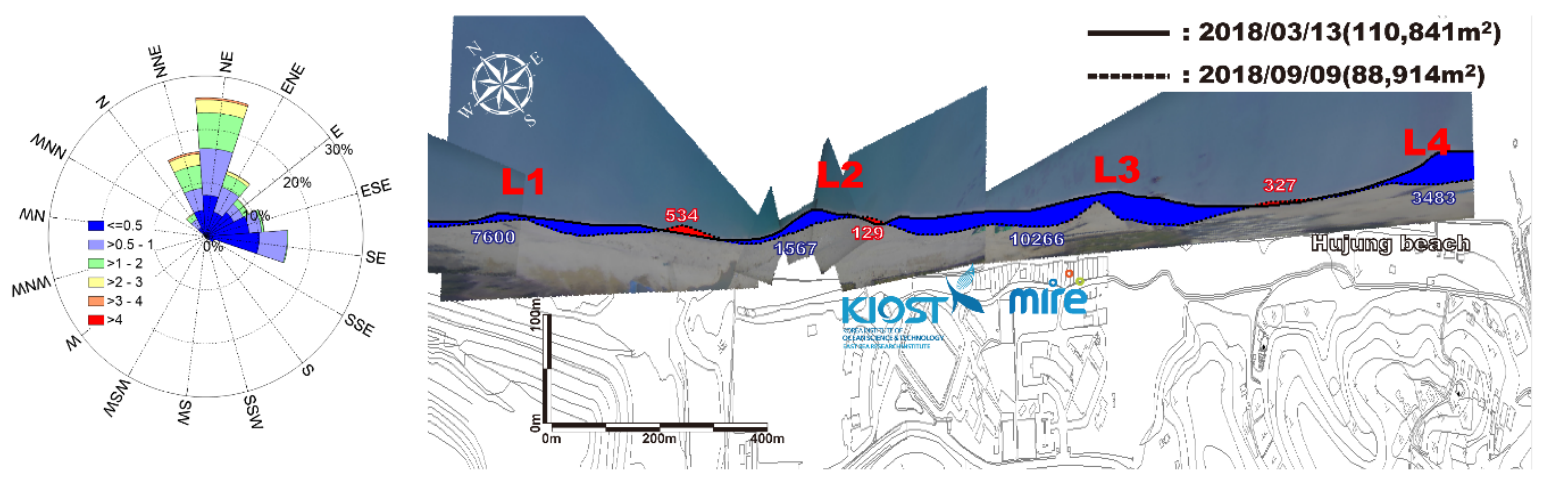

Figure 10. Same comparison as that in Figure 6 but measured at the beginning (13 March 2018) and end (15 August 2018) of T4. 
One evidence on the longshore transport of the sediments near the shore during T4 is found in Figure 11, in which the Google images near L1 and L2 are compared at two times, on 3 March 2018 (T4) and 20 April 2018 (T4). The two times of the captured images belong to the early stage of T4, and they could provide an implication of the littoral process in this period. In Figure 11a,b, the yellow lines mark the positions of the two sandbars as they were drawn to connect the horns and bays of the sandbars. Therefore, these lines compare the orientations of the sandbar development at the two times separated by $\sim 1.5$ months. On 3 March 2018 (T4), the direction of the yellow lines was generally normal to the shoreline. On April 20 (T4), however, the lines were inclined to the north and the angle deviated from the shore at normal direction was $\sim 40^{\circ}$. This indicates that the sediments piled in the sandbars moved to the north due to the shore-parallel waves, which resulted in the sandbar migration along the shore. This migration of sandbars might break the equilibrium status of the out-of-phase coupling of the bars with the shoreline. Thus, the shoreline advance at the corresponding locations of the sandbar horns during $\mathrm{T} 3$ became weaker, which might lead to the flatter shoreline at the end time of T4. At L4, where there is a rocky island instead of sandbars, the shoreline was also significantly retreated probably due to the same shore-parallel waves that carried the sediments along the shore, regardless of the shadowing effect of the island.

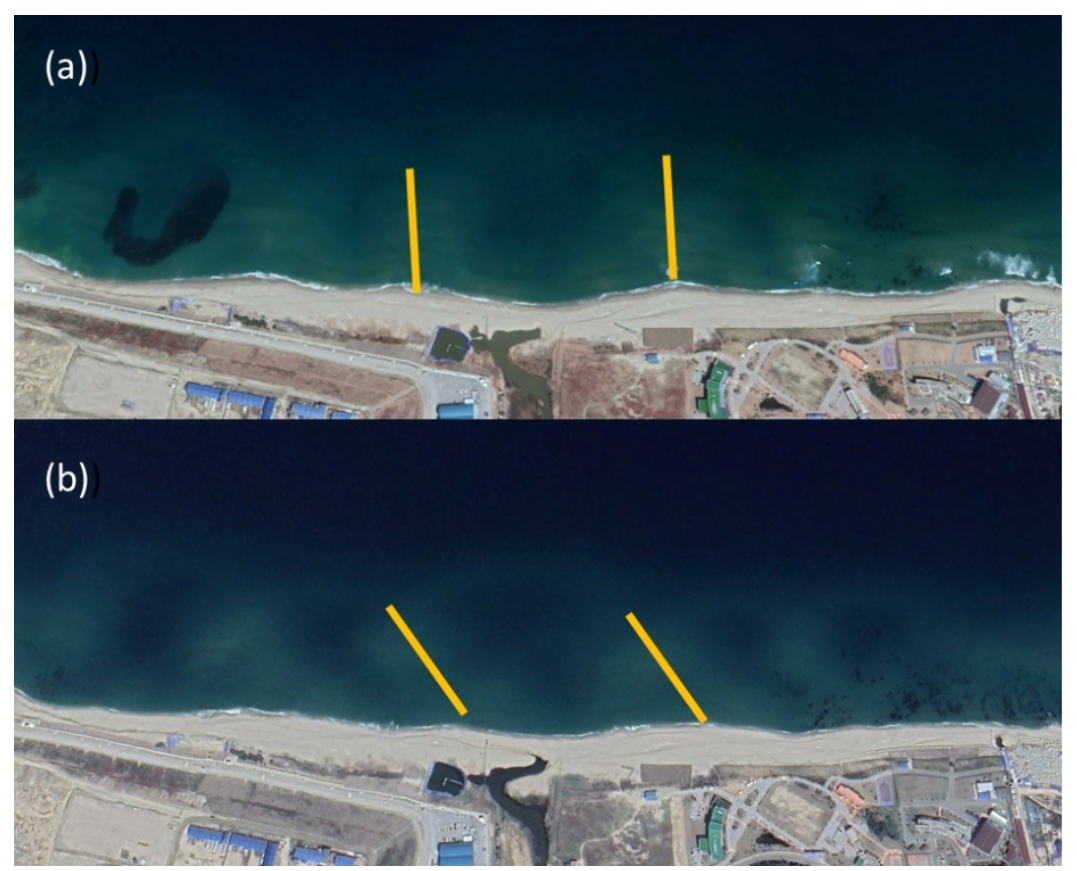

Figure 11. (a) Satellite image captured from Google Earth near L1 and L2 measured on 3 March 2018. (b) Same location but measured on 20 April 2018. The yellow lines denote the orientation of the horns of the sandbars.

\section{Discussion}

The shoreline data provided by the video monitoring shows that $\sim 10 \%$ of $A_{b}$ was lost during the experimental period. The loss of the total beach area indicates that the beach was, in general, under an erosional process, probably due to the blocking of sediments by the breakwater near Bugu River (Figure 1). It should be noted, however, that construction of the breakwater was completed in 1989. Considering that the shoreline data was obtained 27 years after the breakwater construction, the two-year time variation of $A_{b}$ in Figure 4 is not sufficient to confirm that the beach is seriously erosive, and additional data may be required to support the process.

As shown in Figure 9, the seabed topography was occasionally measured using echosounders in Hujeong Beach between July 2016 and July 2018. By comparing the two bathymetry data, the changes in seabed elevation could be calculated to obtain the volume changes in the seabed. The result shows 
that a total of $\sim 99,000 \mathrm{~m}^{3}$ of sand were lost in the nearshore area of the beach during the period. This significant loss of sediment from the nearshore area in Hujeong Beach was continuously observed from the bathymetry data measured at other times, which supports that the beach was in an erosional process probably due to the blocking of sediments by the breakwater. In addition, Figure 12 shows an aerial photograph taken on 28 October 1980 when the intake breakwater near the Bugu River had not been constructed yet. It clearly shows that the waves obliquely approached the shore from the left side of the beach, which probably transported the sediments to the right. However, the sediments in the beach were likely in equilibrium as they were provided through the river. The equilibrium could have been broken after the breakwater was built. The shoreline positions obtained from Figure 12 implies that the beach width might have been reduced by $\sim 15 \mathrm{~m}$ on average since 1980 .

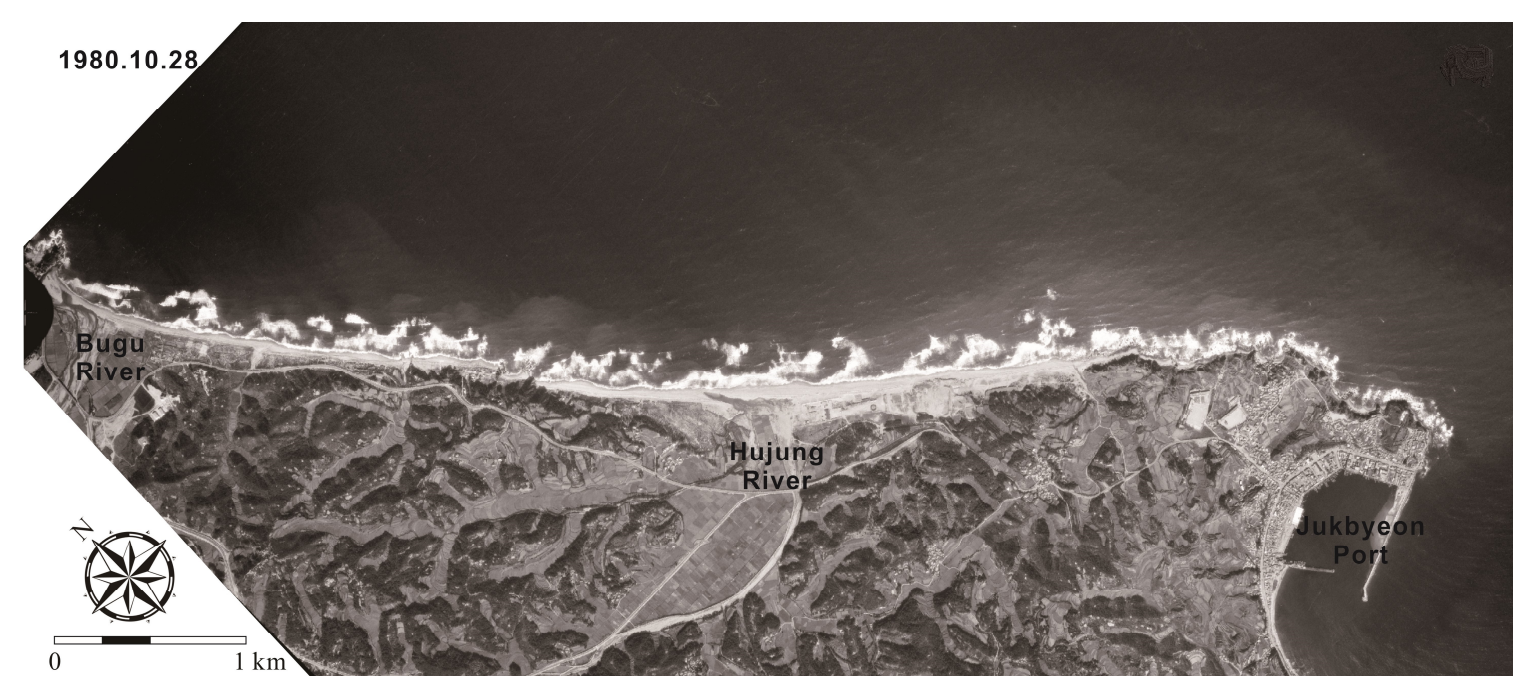

Figure 12. Aerial photograph over the Hujeong Beach area, taken on 28 October 1980 before the breakwater was constructed.

Although the beach was losing the sediments in general, the change in shoreline did not occur uniformly along the coast. Instead, there were locations where the shoreline significantly protruded to make it undulated. This process was closely related to the bottom topography formed by the nearshore sandbars and the underwater rocks that developed at nearshore areas along the beach. Figure 13 shows a satellite image from Google Earth near L1-L3 on 13 February 2019 (after T4). Although the time when the image was taken did not match with the time of T3, it still is a good example that implies the shoreline accretion process during moderate wave conditions. It can be observed in the figure that five crescentic sandbars developed along the shore around L1, L2, and L3. Interestingly, the waves were breaking at the same locations of the sandbar horns. It should also be noted that the shoreline was significantly advanced to the sea at the corresponding locations of the horns, which confirms the out-of-phase coupling of the sandbars with the shoreline. When the waves broke at horn locations due to shoaling, the wave energy in the lee area was reduced to cause a sediment transport gradient in the longshore direction. According to Equation (1), therefore, the shoreline would advance to the sea at these locations. A similar process might be expected in the area near L3 where underwater rocks actively develop. In the rocky area where the water depth was relatively shallower, the waves were easily breaking to cause a longshore sediment transport gradient and the consequent shoreline changes. This is confirmed in Figure 13, which shows that the waves were breaking, and the shoreline protruded at L3 where underwater rocks actively developed. 


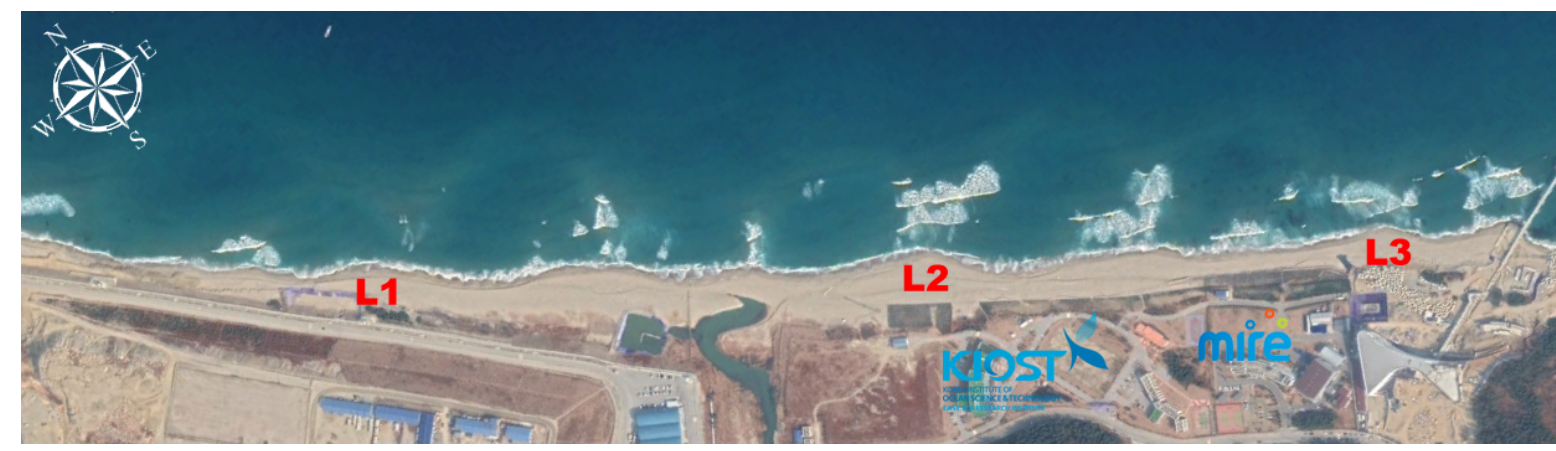

Figure 13. Satellite image captured from Google Earth near L1-L3 measured on 13 February 2019. The image shows that the waves are breaking at the locations where the sandbar horns developed, and the shoreline was advanced at the corresponding locations.

\section{Conclusions}

The shoreline evolution pattern of a sandy beach was investigated using a video monitoring system and wave measurements in Hujeong Beach, Korea. The beach is suspected to be vulnerable to erosion because the input source of sediments has been blocked by construction of a breakwater at the northern end, while the beach continues to lose sand at the opposite end. The beach is also characterized by crescentic sandbars that actively develop in the northern part of the nearshore region. In the other side of the beach, the seabed is covered by numerous underwater rocks. In addition, a rocky island is located at the southern end of the beach. These sandbars and rocky structures played significant roles in shaping the beach shorelines in concert with the incoming waves. During the two-year period of the observation, the overall area of the beach decreased $\sim 10 \%$. However, there were times when the beach area rapidly increased, which made the time variation pattern of beach evolution highly complicated. The erosion or accretion of the shoreline generally agreed with the expected situation based on the wave conditions. However, the response of the beach to a short-term storm event such as Typhoon Kong Rey was not clearly recorded. The video monitoring data was difficult to measure owing to the harsh weather during the storm.

The results showed that the beach area increased when the waves obliquely approached the shore, whereas it decreased when the waves approached in a normal direction to the shore, even though the wave energy was not clearly differentiated between them. In addition, the accretion of the shoreline did not occur uniformly along the beach. Instead, there were locations where the shoreline significantly protruded toward the sea. These areas corresponded to the locations where the horns of sandbars developed, which showed an example of out-of-phase coupling between the sandbars and the shoreline. As an evidence, the waves were observed to break at the same locations as the horns, which indicates that the wave energy in the lee areas of the horns was reduced to produce a longshore sediment transport gradient, resulting in shoreline accretion. Along with the sandbars, underwater rocks developed in the southern part of the beach. These rocks played a similar role to that of the sandbars, breaking the waves to produce a sheltering area in the lee. When the waves approached the shore in a normal direction, the longshore drift of sediment became weaker and offshore sediment transport occurred uniformly along the coast, which made the shoreline to become flatter. The results of this study indicate that the incoming wave directions are important in shaping the sandy shorelines, and this must be considered when designing beach facilities and coastal structures for various purposes. In addition, the seabed topography and the distribution of bedforms should be carefully investigated as they may also affect the shoreline evolution pattern. In this study, the examples of in-phase coupling between the sandbars and the shoreline have not been observed, which is expected to occur under different wave conditions and will be investigated in future studies.

Author Contributions: The contributions of each author are as follows: conceptualization, Y.S.C., J.-D.D., W.M.J. and J.-Y.J.; methodology, J.-D.D. and C.H.K.; formal analysis, J.-D.D. and Y.S.C.; investigation, J.-D.D. and Y.S.C.; resources, J.-D.D., W.M.J., C.H.K. and J.-Y.J.; data curation, J.-D.D.; writing-original draft preparation, J.-D.D. and 
Y.S.C.; writing-review and editing, J-.D.D. and J.-Y.J.; visualization, J.-D.D. and Y.S.C.; project administration, Y.S.C. and J.-Y.J.; funding acquisition, Y.S.C. and J.-Y.J.

Funding: This research was funded by the Korea Institute of Ocean Science and Technology (KIOST), grant number PE99731.

Conflicts of Interest: The authors declare no conflict of interest.

\section{References}

1. Lippmann, T.C.; Holman, R.A. Quantification of sand bar morphology: A video technique based on wave dissipation. J Geophys. Res. 1989, 94, 9951011. [CrossRef]

2. Plant, N.G.; Holman, R.A. Intertidal beach profile estimation using video images. Mar. Geol. 1997, 140, 1-24. [CrossRef]

3. Aarninkhof, S.G.; Turner, I.L.; Dronkers, T.D.; Caljouw, M.; Nipius, L. A video-based technique for mapping intertidal beach bathymetry. Coast. Eng. 2003, 49, 275-289. [CrossRef]

4. Davidson, M.A.; Aarninkhof, S.G.J.; Van Koningsveld, M.; Holman, R.A. Developing Coastal Video Monitoring Systems in Support of Coastal Zone Management. J. Coast. Res. 2006, 1, 49-56.

5. Chickadel, C.; Holman, R.A. Measuring longshore currents with video techniques. In EOS Trans, Fall Meeting; American Geophysical Union: Washington, DC, USA, 2002; Volume 82.

6. Holmann, R.A.; Stanley, J. The history and technical capabilities of Argus. Coast. Eng. 2007, 54, 477-491. [CrossRef]

7. Yoon, J.; Song, D. Preliminary study for detecting of ocean wave parameters using CCD images. J. Coast. Res. 2018, 85, 1371-1375. [CrossRef]

8. Ojeda, E.; Guillén, J. Monitoring beach nourishment based on detailed observations with video measurements. J. Coast. Res. 2006, 48, 100-106.

9. Vousdoukas, M.I.; Almeida, L.P.M.; Ferreira, Ó. Beach erosion and recovery during consecutive storms at a steep-sloping, meso-tidal beach. Earth Surf. Process. Landf. 2012, 37, 583-593. [CrossRef]

10. Holland, K.T.; Holman, R.A.; Lippmann, T.C.; Stanley, J.; Plant, N. Practical use of video imagery in nearshore oceanographic field studies. IEEE J. Ocean. Eng. 1997, 22, 8192. [CrossRef]

11. Chang, Y.S.; Do, J.-D.; Kim, S.-S.; Ahn, K.; Jin, J.-Y. Measurement of turbulence properties at the time of flow reversal under high wave conditions in Hujeong Beach. J. Korean Soc. Coast. Ocean Eng. 2017, 29, $206-216$. [CrossRef]

12. Korea Institute of Ocean Science and Technology (KIOST). Development of fundamental technology for coastal erosion control. Tech. Rep. 2018, 5, 43-52.

13. Zhang, Y.; Wetherill, B.R.; Chen, R.F.; Peri, F.; Rosen, P.; Little, T.D.C. Design and implementation of a wireless video camera network for coastal erosion monitoring. Ecol. Inform. 2014, 23, 98-106. [CrossRef]

14. Jagalingam, P.; Akshaya, B.J.; Hedge, A.V. Bathymetry mapping using Landsat 8 satellite imagery. Procedia Eng. 2015, 116, 560-566. [CrossRef]

15. Pacheo, A.; Horta, J.; Loureiro, C.; Ferreira, Ó. Retrieval of nearshore bathymetry from Landsat 8 images: A tool for coastal monitoring in shallow waters. Remote. Sens. Env. 2015, 159, 102-116. [CrossRef]

16. Pelnard-Considere, R. Essai de Theorie de l'Evolutio des Form de Rivage en Plage de Sable et de Galets. 4th Journees de l'Hydaulique, Les Energies de la Mer, Question III 1956, 1, $289-298$.

17. Korea Institute of Ocean Science and Technology (KIOST). Advanced Operation of the Coastal Hydrodynamics and Beach Erosion Monitoring System Infra in Hujeong. Tech. Rep. 2019, 7, 57-65.

18. Price, T.D. Morphological Coupling in a Double Sandbar System. Ph.D. Thesis, Utrecht University, Utrecht, The Netherland, 2013.

19. Price, T.D.; Ruessink, B.G.; Castelle, B. Morphological coupling in multiple sandbar systems-A review. Earth Surf. Dyn. 2014, 2, 309-321. [CrossRef]

(C) 2019 by the authors. Licensee MDPI, Basel, Switzerland. This article is an open access article distributed under the terms and conditions of the Creative Commons Attribution (CC BY) license (http://creativecommons.org/licenses/by/4.0/). 